\title{
Sobre la comisión parlamentaria de investigación de la FAFFE y sus comparecientes mudos
}

\author{
Víctor F. Vázquez Alonso
}

Creo que puede decirse que la comisión de investigación es una de las instituciones de derecho parlamentario con peor implantación en nuestra cultura democrática, siendo este un juicio que no se basa en criterios puramente cuantitativos, sino en la propia escenificación y en los resultados de las hasta ahora llevadas a cabo. No han sido extrañas, en este sentido, las comisiones de investigación en las que se ha producido una suerte de modificación en los papeles propios de tal instituto, convirtiéndose los parlamentarios en el objeto de control de los comparecientes y desdibujándose así, ante la opinión pública, los contornos propios de un instrumento capital para la rendición de cuentas. Desde luego, a esta disfuncionalidad en la práctica parlamentaria ha colaborado una cierta indefinición jurídica en aspectos no poco relevantes de su regulación, indefinición que se agudiza cuando descendemos al ámbito parlamentario autonómico. A este respecto, la Comisión de investigación creada en el Parlamento Andaluz el día 25 de febrero de 2019, con la aquiescencia de todos los grupos parlamentarios y sobre el Fondo de Formación y Empleo (FAFFE), ha puesto sobre la mesa una de las cuestiones más controvertidas sobre este asunto que es la del alcance de la obligación de comparecencia por parte de aquellos que son requeridos por las cámaras.

Desde luego, hay un elemento cronológico al que es necesario hacer mención para contextualizar la suerte de estampida o enmudecimiento sobrevenido que se ha producido con respecto a algunos de los comparecientes requeridos por el Parlamento andaluz, y es el de que, con el acuerdo de los grupos parlamentarios que en la actualidad conforman la coalición de gobierno andaluza, se citara a declarar a antiguos cargos políticos del partido socialista justo la semana en la que se celebraban las elecciones generales al Parlamento español. Una circunstancia que, se entiende, podría empañar la neutralidad institucional del Parlamento con respecto al procedimiento electoral en curso. En cualquier caso, ante esta situación podemos distinguir tres comportamientos diferenciados por parte de los comparecientes requeridos.

En primer lugar, algunos de ellos no han comparecido porque ha resultado imposible notificarles la citación. Se trata, en este caso, de la expresidenta Susana Díaz y del expresidente José Griñán, "ilocalizables" ambos, a los efectos de proceder con la pertinente notificación de su citación parlamentaria. 
En segundo lugar, otros citados sí han comparecido si bien negándose a someterse a las preguntas de los distintos portavoces de los grupos parlamentarios. A este respecto, el expresidente Manuel Chaves aprovechó su comparecencia para hacer pública su oposición a la forma en la cual se había procedido por parte de la Comisión subrayando la circunstancia de que "tres expresidentes, dos expresidentes y una expresidenta, y una ministra del Gobierno de España han sido citados 72 y 48 horas antes del día 10, que es el día de la fecha electoral", algo que en su opinión era "contrario a la neutralidad política del parlamento". Además de esto, el expresidente Chaves se acogió a su derecho a guardar silencio, rechazando en los siguientes términos su oposición a que se le realizara cualquier pregunta por parte de los portavoces de los grupos parlamentarios:

"tengo el derecho a guardar silencio y tengo también derecho a no declarar. Y tengo también el derecho a que no se me violente en mi derecho a guardar silencio en esta comisión. En consecuencia, si se va a proceder al turno de las preguntas, las preguntas considero que constituyen una violación de mi derecho a guardar silencio"

También se acogió a su derecho a guardar silencio el exconsejero Ramírez Arellano, en su comparecencia del día 8 de noviembre, justificando su opción en unos términos que, dada su brevedad, creo que vale la pena reproducir íntegramente:

"comparezco ante esta comisión de investigación por haber sido consejero de Economía, Hacienda y Administración Pública entre junio de 2018 y enero de 2019, es decir, poco más de seis meses, varios de los cuales, como les consta a sus señorías, han sido en funciones. En ese tiempo no tuve conocimiento sobre la materia que es objeto de esta comisión de investigación, ni me consta que así haya sido entre mis colaboradores más cercanos. Estoy seguro, por otro lado, porque es información material que esta comisión pudiera requerir, que seguro que puede, en fin, que puede producirse, podrá ser atendida por el actual consejero de Hacienda, señor Bravo, al que entiendo que también llamarán a esta comisión. Por lo demás, y dicho eso, me acojo a mi derecho de no responder a las preguntas de sus señorías y doy por cumplida mi obligación de comparecer ante esta comisión"

Esa misma sesión, también abandonó la comparecencia Javier Carnero Sierra, acogiéndose a su derecho a no declarar, tras afirmar que:

“...no existe ni razón jurídica ni razón práctica que justifique de ninguna manera la imperiosa necesidad de celebrar las sesiones precisamente los días que han sido convocadas, del mismo modo que no existe ni fundamento jurídico ni razón práctica para justificar el cambio de orden de las comparecencias, o tampoco existe ni fundamento jurídico ni razón práctica para alterar el orden natural de intervenciones de los grupos parlamentarios." 
Un caso distinto es el de la actual Ministra de Hacienda, María Jesús Montero, quien informó por escrito al Parlamento que no acudiría a la comparecencia requerida, al considerar, como se insistirá al final, que hay precedentes suficientes para negar la obligación de comparecencia de los miembros del ejecutivo estatal en las comisiones de investigación autonómicas.

Como señalábamos al comienzo, esta cuando menos caótica comisión de investigación ha situado en un primer plano la cuestión del alcance de la obligación de comparecer en dichas comisiones. El marco normativo de la cuestión, parte, como es conocido, del artículo 76 de la propia Constitución que establece lo siguiente:

1. El Congreso y el Senado, y, en su caso, ambas Cámaras conjuntamente, podrán nombrar Comisiones de investigación sobre cualquier asunto de interés público. Sus conclusiones no serán vinculantes para los Tribunales, ni afectarán a las resoluciones judiciales, sin perjuicio de que el resultado de la investigación sea comunicado al Ministerio Fiscal para el ejercicio, cuando proceda, de las acciones oportunas.

2. Será obligatorio comparecer a requerimiento de las Cámaras. La ley regulará las sanciones que puedan imponerse por incumplimiento de esta obligación.

Por su parte, la Ley Orgánica 5/ 1984, de 24 de mayo, de comparecencia ante las Comisiones de investigación· del Congreso y del Senado o de ambas Cámaras, desarrolló esta obligación en los siguientes términos:

1. Todos los ciudadanos españoles y los extranjeros que residan en España están obligados a comparecer personalmente para informar, a requerimiento de las Comisiones de Investigación nombradas por las Cámaras Legislativas.

2. Las Mesas de las Cámaras velarán por que ante las Comisiones de Investigación queden salvaguardados el respeto a la intimidad y el honor de las personas, el secreto profesional, la cláusula de conciencia y los demás derechos constitucionales.

Y el Código Penal, en términos expresamente extensivos al ámbito parlamentario autonómico, establece en su artículo $502^{1}$, que serán castigados serán castigados como reos del delito de desobediencia.

1. Los que, habiendo sido requeridos en forma legal y bajo apercibimiento, dejaren de comparecer ante una Comisión de investigación de las Cortes Generales o de una Asamblea Legislativa de Comunidad Autónoma...

1 Reforma introducida por la Ley Orgánica 19/1995 de 23 de noviembre. 
La creación de comisiones de investigación está prevista por el Estatuto de Andalucía que en su artículo 106.3, al referirse al "control sobre la acción del Consejo de Gobierno y sobre la acción de la Administración situada bajo su autoridad”, y en donde se establece "se podrán crear, en su caso, comisiones de investigación, o atribuir esta facultad a las comisiones permanentes".

El Reglamento del Parlamento Andaluz, por lo que aquí interesa, prevé en el número 2 del Artículo 52 que:

"Las Comisiones de Investigación elaborarán un plan de trabajo y podrán nombrar Ponencias en su seno, así como requerir la presencia, por conducto de la Presidencia del Parlamento, de cualquier persona para que sea oída. Los extremos sobre los que deba informar la persona requerida deberán serle comunicados con quince días de antelación, salvo cuando, por concurrir circunstancias de urgente necesidad, se haga con un plazo menor, que en ningún caso será inferior a tres días. En la notificación, dicha persona será informada de sus derechos y obligaciones conforme a lo dispuesto en este Reglamento, y podrá comparecer acompañada de quien designe para asistirla".

Delimitado el marco normativo, cabe hacer una breve reflexión sobre la necesidad de atender a los matices que diferencian el comportamiento de unos y otros, a la hora de poder circunscribir mejor cuál puede ser el alcance jurídico de las responsabilidades de uno y de otro.

A este respecto, y en relación a quienes se han acogido a su derecho a no declarar, cabe subrayar que dicho derecho, consagrado en el artículo 24 de la Constitución, es un derecho de naturaleza netamente procesal. En este sentido, es por lo menos dudosa su invocación en un ámbito, como el de las comisiones de investigación parlamentaria, donde no se depuran responsabilidades jurídicas sino puramente políticas. No obstante, no puede descartarse que dicho derecho despliegue sus efectos cuando alguna de las personas cuya comparecencia es requerida sea a su vez objeto de un proceso o investigación judicial, tal y como era el caso de Manuel Chaves. Fuera de estos casos la invocación del artículo 24 creo que resulta desubicada. Cabe plantearse, en cualquier caso si el mero silencio durante las comparecencias es equiparable a la incomparecencia, sancionada por el artículo 502 del Código Penal como un delito de desobediencia específica, y ello en tanto, no son sino quienes han sido requeridos por cualquier cámara los que pueden desobedecer de esta forma típica. Desde luego, no puede ser una mera crónica como la que aquí se lleva a cabo el lugar para dar una respuesta concluyente a esta pregunta, no obstante, parece evidente que de aceptarse de forma normalizada la posibilidad de guardar silencio en este tipo de comisiones cuando se cuestione la pertinencia de su creación o de la propia citación parlamentaria, se estaría devaluando de forma letal la comisión de investi- 
gación como instituto de control parlamentario. A este respecto, las causas motivadas de silencio vienen establecidas, como se ha visto, por la propia ley Ley Orgánica 5/ 1984, de 24 de mayo, y se concretan en la intimidad y el honor de las personas, el secreto profesional, la cláusula de conciencia y los demás derechos constitucionales. Esta apelación final a "los demás derechos fundamentales" sirve como manto para la propia indemnidad del artículo 24.2, evitando que a través de las mismas se puedan ver afectados los derechos de defensa de quien se encuentre inmerso en algún tipo de proceso, pero no creo que de la misma se pueda deducir una salvaguarda general del derecho a no declarar, o por lo menos, no sin un profundo menoscabo de este instrumento parlamentario de control. No conviene olvidar que es la propia Constitución la que quiere que una de las funciones de las cámaras de representación democrática sea la de poder cotejar en beneficio del interés público aquellos asuntos que estas consideren, instando desde la propia Constitución a la sanción de quien desobedezca el requerimiento de comparecencia de la Cámara.

En cualquier caso, algunos precedentes recientes dejan ver cierta deferencia hacia la licitud del comportamiento de los comparecientes mudos. Así, la fiscalía de Madrid ha rechazado recientemente llevar a cabo acciones legales frente a una compareciente que se negó a declarar ante la Comisión de Investigación sobre partidos políticos constituida en el Senado, al entender que esta conducta está amparada por el artículo 24.2 de la Constitución y por lo tanto no es constitutiva de delito ${ }^{2}$. Del mismo modo, existe un precedente en propio Parlamento andaluz, cuando en la Comisión de Investigación de los ERE, el que fuera delegado de Empleo de la Junta en Sevilla, Antonio Rivas, se negó a responder acogiéndose igualmente a seste derecho procesal. Una conducta que según el informe los servicios jurídicos de la Cámara no era constitutiva de delito de desobediencia.

Para concluir, ha de hacerse mención a la incomparecencia anunciada por la ministra Montero. Como ha ocurrido en otras experiencias autonómicas, y siempre sobre la base de diversas decisiones del Consejo de Estado ${ }^{3}$, la incomparecencia de altos cargos del Estado en comisiones de investigación autonómicas se legitima a partir de una interpretación de estas comisiones de investigación como instrumentos de control circunscritos de forma estricta al gobierno y a la administración autonómica. Una interpretación que confirma, por un lado, la dificultad con la que la lógica que se deduce del artículo 76 de la Constitución se traslada al ámbito parlamentario autonómico, y, al mismo tiempo, la devaluación general de este instituto dentro del sistema político español.

\footnotetext{
2 No se ha podido tener acceso al documento de la fiscalía, parece que sí pudo eldiario.es : https://www.eldiario.es/politica/fiscal-negarse-declarar-comision-investigacion_0_865464139.html

3 DCE 406/2013; DCE 406/2017.
} 